\title{
ПРАВОВОЕ САМОРЕГУЛИРОВАНИЕ КАК ВИД ПРАВОВОГО РЕГУЛИРОВАНИЯ
}

\author{
(c) 2021 Петрик Анжелика Сергеевна \\ аспирант \\ Иркутский институт (филиал) Всероссийского государственного университета юстиции \\ (РПА Минюста России) \\ E-mail: petrik.yurist.irk@mail.ru
}

Статья посвящена вопросам определения правовой природы правового саморегулирования. В целях ответа на поставленный вопрос автором исследованы соотношение признаков правового регулирования и правового саморегулирования, а также соотношение элементов их механизмов.

Таким образом, в статье сформирован тезис о том, что правовое саморегулирование является видом правового регулирования.

Ключевые слова: правовое регулирование; саморегулирование; правовое саморегулирование; механизм правового регулирования; механизм правового саморегулирования; предмет правового саморегулирования; метод правового саморегулирования; пределы правового саморегулирования; признаки правового саморегулирования.

Правовое саморегулирование, как инструмент упорядочения отдельных видов общественных отношений, в последние десятилетия получает широкое распространение как в теории права, так и в практической юридической деятельности.

Понятие саморегулирования в контексте способа регулирования общественных отношений является относительно новым и проработано в меньшей степени, нежели классические регуляторы общественных отношений. В связи с чем представляет интерес вопрос о правовой природе саморегулирования.

Рассмотрим для начала сам термин «саморегулирование» безотносительно к праву. Существуют широкий и узкий подходы к его определению.

В широком смысле под саморегулированием понимается наличие в определенной системе элементов свойств, позволяющих самостоятельно, без воздействия извне, устанавливать, поддерживать желаемый режим своего функционирования и реагировать на внешние воздействия.

Использование термина «саморегулирование» в узком смысле применительно к отдельным отраслям науки и общественной жизни, среди которых, экономика, право, социология, позволило многим ученым не только выявить особенности саморегулирования, которые свойственны определенной области научного познания, но и, как следствие, дать определение саморегулированию с позиции той или иной науки.
Так, с точки зрения юридической науки, саморегулирование является одной из форм индивидуального правового регулирования.

Под индивидуальным правовым регулированием понимают такое правовое воздействие на общественные отношения, которое связано с установлением, изменением или прекращением юридических прав и обязанностей их участников в индивидуальном порядке, направлено на урегулирование конкретных ситуаций, требующих юридического разрешения, и осуществляется путем совершения односторонних правомерных юридически значимых действий или заключения договоров либо властной правоприменительной деятельности уполномоченных субъектов, в процессе которого создаются индивидуальные правовые акты [3, с. 42].

Нормы права крайне редко распространяются на всех субъектов без исключения. Предпосылки индивидуального правового регулирования посредством правовой персонификации закладываются законодателем еще на уровне нормативного правового регулирования [4, с. 69].

Являясь формой индивидуального правового регулирования правовое саморегулирование в узком смысле представляет собой самостоятельную и инициативную деятельность субъектов для достижения своих целей в рамках законодательства, направленную на упорядочение конкретных общественных отношений посредством создания индивидуально-правового предписания [1, с. 48]. 
В данном случае важно отметить, что индивидуально-правовое предписание здесь предполагает не акт правоприменения, направленный на конкретный субъект правоотношения, а определенный акт, хотя и не обладающий признаком нормативности в полной мере, но сохраняющий обязательность для круга лиц (как определенного, так и не определенного), сформированного по какому-либо общему критерию: общие цели, проблемы, сфера профессиональной деятельности и т.д.

В зависимости от таких критериев можно определить сферы общественных отношений, где регулятором выступает правовое саморегулирование.

В частности, саморегулирование становится одним из важнейших способов регулирования предпринимательской деятельности.

Сфера предпринимательских правоотношений регулируется посредством норм саморегулирования не только в силу волеизъявления их субъектов, но и поскольку существует прямое указание законодателя на возможность и должность применения саморегулирования для этой сферы.

Так, согласно статье 2 Федерального закона от 01.12.2007 № 315-Ф3 «О саморегулируемых организациях», под саморегулированием понимается самостоятельная и инициативная деятельность, которая осуществляется субъектами предпринимательской или профессиональной деятельности и содержанием которой являются разработка и установление стандартов и правил указанной деятельности, а также контроль за соблюдением требований указанных стандартов и правил [4].

Данное определение распространяется лишь на прямо определенный круг общественных отношений, в связи с чем в целях настоящего исследования сохраняет свою актуальность понятие саморегулирования, предлагаемое наукой государства и права.

Объединяя вышеизложенные подходы к определению правового саморегулирования, полагаем возможным уточнить понятие правового саморегулирования следующим образом.

Правовое саморегулирование в юридической науке представляет собой одну из форм индивидуального правового регулирования, для которой характерно осуществление правового регулирования без государственного вмешательства, путем самостоятельной и инициатив- ной деятельности субъектов предпринимательской или профессиональной деятельности, а также лиц, объединенных иными общими целями и/или признаками, для упорядочения конкретных общественных отношений, связанных с деятельностью данных субъектов, и обязательное для них.

Данное определение отражает юридический подход к понятию саморегулирования, также его можно назвать узким.

В широком смысле в рамках юридического подхода следует понимать любую деятельность субъектов, направленную на урегулирование их отношений путем установления определенных правил за рамками государственного вмешательства или при его минимальном проявлении.

Комплексный анализ определений позволяет выделить следующие его признаки:

- Правовое саморегулирование - это самостоятельная (без внешнего воздействия) и инициативная деятельность субъектов.

Данный признак следует рассмотреть в два этапа. Во-первых, он означает, что саморегулирование - это деятельность, то есть для его реализации соответствующий субъект осуществляет ряд действий, объединенных единой целью. Во-вторых, это деятельность самостоятельная и инициативная, что означает, что для ее осуществления не требуется какого-либо указания вышестоящего лица, органа или организации, равно как и не осуществляется контроль за такой деятельностью.

- Цель саморегулирования - упорядочение конкретных общественных отношений. Саморегулирование не возникает в отрыве от конкретных общественных отношений, не может распространяться на неопределенный круг лиц и неопределенное количество повторяющихся ситуаций, акты саморегулирования издаются соответствующими субъектами при необходимости урегулирования ими конкретных общественных отношений, возникающих по поводу связи вышеуказанных субъектов.

- Итог саморегулирования - создание индивидуально-правового предписания. Как указывалось выше, саморегулирование является деятельностью. Ее итогом становится издание индивидуально-правового акта, в котором отображаются способы регулирования общественных отношений в той сфере, для которой данный акт разрабатывается, а также для субъектов, деятельность которых подпадает под данный акт. 
- Саморегулирование осуществляется в сфере права, что характеризует его именно как правовое саморегулирование.

- Обязательность для конкретного круга лиц (как индивидуально-определенного, так и нет), сформированного по какому-либо общему критерию: общие цели, проблемы, сфера профессиональной деятельности и т.д.

Дополнительно из легального определения саморегулирования выделяются следующие признаки.

- Саморегулирование осуществляется субъектами предпринимательской или профессиональной деятельности. Данный признак, отраженный в Федеральном законе «О саморегулируемых организациях», означает что в контексте данного нормативного акта саморегулирование распространяется только на сферу предпринимательской и профессиональной деятельности. Для целей настоящего исследования указанный признак следует изложить расширительно, с учетом теоретического определения понятия «саморегулирование», что означает увеличить круг субъектов правового саморегулирования, включив сюда не только субъекты предпринимательской и профессиональной деятельности, но также субъекты гражданских и трудовых правоотношений, ряд субъектов публичного права и надгосударственные образования.

- Саморегулирование как специальная деятельность выражена в разработке стандартов такой деятельности, их установление и контроль за соблюдением. Данный признак дополняет положение о том, что итогом саморегулирования выступает индивидуально-правовое предписание в конкретной сфере. Так, из легального определения саморегулирования следует, что данное предписание не только должно быть разработано, но также его действие подлежит обязательному распространению на всех субъектов, причастных к соответствующей группе лиц, то есть такие субъекты должны быть извещены о наличии соответствующего предписания, а также о необходимости его соблюдать, что обеспечивается контролем создавшего такое предписание субъекта.

Исходя из чего можно сделать вывод о том, что правовое саморегулирование находит место в системе правового регулирования как его вид, сочетающий в себе основные признаки правового регулирования, а также имеющий ряд соб- ственных признаков, позволяющих индивидуализировать его.

Из анализа системы правового регулирования следует, что оно включает в себя два самостоятельных вида: нормативное и индивидуальное правовое регулирование, при этом индивидуальное регулирование включает в себя автономное, координационное и субординационное регулирование. В виду наличия у первых двух видов такого признака, как возможность его субъектов самостоятельно определять линию своего поведения, они, объединяясь, образуют правовое саморегулирование, что позволяет определить место правового саморегулирования в системе правового регулирования как подвид одного из двух основных видов правового регулирования. Самоорганизация при этом является самостоятельным правовым явлением и не относится к системе правового регулирования, существует самостоятельно, в определенной взаимосвязи с правовыми методами регулирования общественных отношений.

Несмотря на новизну понятия правового саморегулирования и его меньшую в сравнении с иными общественными регуляторами научной проработанностью, оно имеет свои теоретические характеристики.

К элементам механизма правового саморегулирования относятся предмет, методы, типы, пределы правового саморегулирования.

Также в качестве характеристик правового саморегулирования можно назвать стадии создания и действия норм правового саморегулирования, цели правового саморегулирования.

Сравнительная характеристика механизма правового регулирования и правового саморегулирования демонстрирует, что отличия между правовым регулированием и правовым саморегулированием отсутствуют в отношении предмета, способов внешнего выражения норм правового регулирования и саморегулирования, а также порядка действия таких норм.

В иных критериях для сравнения присутствует ряд отличий. Так, к ключевым отличиям целей правового регулирования и саморегулирования относится то, что саморегулирование призвано обеспечить представление отдельных групп субъектов, распространено лишь в отдельных сферах общественной жизни или их частях.

Из общего сравнительного анализа характеристик правового регулирования и саморегулирования, и с учетом положений о соотношении 
категорий общего и целого, следует, что правовое саморегулирование является одним из видов правового регулирования.

Вышеизложенные характеристики правового саморегулирования являются отправными началами теоретического анализа правового саморегулирования как самостоятельного вида правового регулирования, дают основания для более детальной теоретической проработки соответствующего способа регулирования общественных отношений.

\section{Библиографический список}

1. Лескова Ю.Г. Саморегулирование как экономическое и правовое явление // Журнал российского права. 2011. № 5. С. 48-56.

2. Минникес И. А. Об индивидуальной норме и индивидуальном правовом регулировании // Российский юридический журнал. 2009. № 5. С. 69-74.

3. Минникес И.А. Понятие правовой персонификации (к проблеме индивидуального правового регулирования) // Известия Байкальского государственного университета. 2006. № 6. С. $42-45$.

4. О саморегулируемых организациях: Федер.закон Рос.Федерации от 01 декабря 2007 г. N 315-Ф3: принят Гос. Думой Федер. Собр. Рос. Федерации 16 нояб. 2007 г.: одобр. Советом Федерации Федер. Собр. Рос. Федерации 23 нояб. 2007 г. // Рос. газ. - 2007. - 06 декабря. N 273 